\title{
SERTOLI-LEYDIG CELL TUMOR: A RARE OVARIAN TUMOR
}

Lavanya Kumari Sarella ${ }^{1}$, D. Usha Sree ${ }^{2}$

\section{HOW TO CITE THIS ARTICLE:}

Lavanya Kumari Sarella, D. Usha Sree. "Sertoli-Leydig Cell Tumor: A Rare Ovarian Tumor". Journal of Evolution of Medical and Dental Sciences 2014; Vol. 3, Issue 14, April 07; Page: 3657-3660,

DOI: $10.14260 /$ jemds/2014/2337

ABSTRACT: Sertoli- Leydig cell tumor or "Androblastoma" or "Arrhenoblastoma" is a rare virilizing tumor of ovary, mostly with masculinizing features. Many but certainly not all tumors are hormonally active. Although classified under malignant tumors the degree of malignancy is less than that of ovarian carcinoma in general. Unilateral oophorectomy was done and the patient recovered well with diminution of masculinizing features.

KEYWORDS: Clitoromegaly, Hirsutism, Sertoli- Leydig cell tumor, Testosterone.

INTRODUCTION: Sertoli-Leydig cell tumor (SLCT) is a rare ovarian tumor that belongs to the group of sex-cord stromal tumors. These constitute less than $0.5 \%$ of ovarian tumors .Most tumors are unilateral, seen during the second and third decades of life and are of less well differentiated variety. Many patients have symptoms of virilization due to the presence of androgen element in tumor. The degree of differentiation is age related. ${ }^{1}$ Intermediate differentiated tumors comprises of $54 \%$ of tumors (data reference 2).

CASE: A 20 year old nulliparous unmarried woman came to Government general hospital with complaints of progressive oligomenorrhoea of one and half years duration. She had been amenorrhic for the past one and half year. She had noticed excessive growth of hair on face, chest and limbs and hoarseness of voice for one year, recession of breast (and increased sweating and fatigue for one year).Headache for 10years which is occipital in nature with nausea and reeling sensation and relieved on taking some analgesic. There is no history of anorexia, weight loss/gain. Her medical and family history is uneventful.

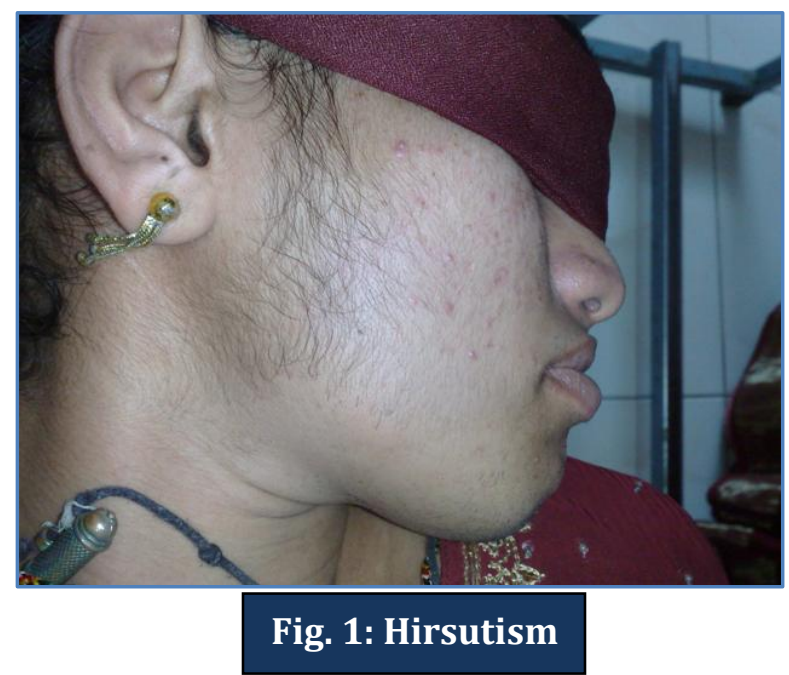

Her general physical examination was normal except for the presence of hirsutism FERRIMAN-GALLWAY score of 13 , and clitoromegaly. Per rectal examination revealed normal 


\section{CASE REPORT}

findings. An ultrasound examination of the pelvis showed $5 \times 4.2 \mathrm{cms}$ solid mass in left adnexa, and MRI abdomen showed $4.3 \times 3.6 \mathrm{cms}$ solid space occupying lesion in left ovary. Hormone profile in blood indicated excessive androgenic activity in the form of elevated testosterone level. (513ng/dl; normal 20-80ng/dl), serum and rostenidione $(7.66 \mathrm{ng} / \mathrm{ml}$; normal.3-3.5ng/ml), DHEA $(81.7 \mathrm{ng} / \mathrm{ml}$; normal 1.8-12.5ng/ml).however DHEAS levels were normal. MRI brain, visual fields, and fundus examination were normal.

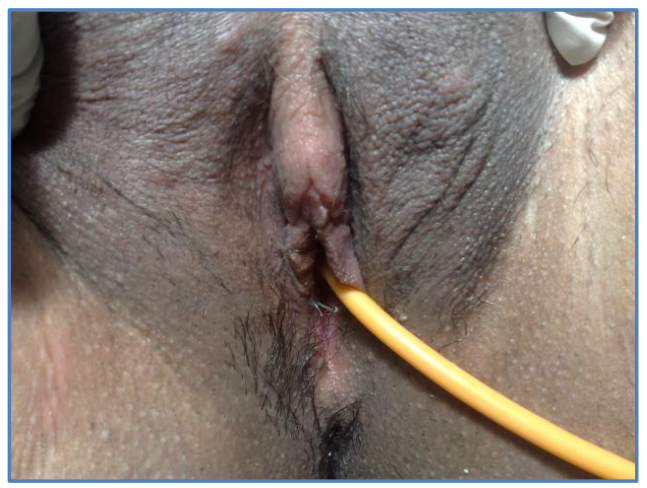

Fig. 2: Clitoromegaly

Based on these investigations a diagnosis of virilizing (androgen producing) tumor of ovary was made. The patient underwent exploratory laparotomy and left salpingo-oophorectomy. The size of the left ovary is $7 \times 5 \mathrm{cms}$ and on cut section showed a well encapsulated $5 \times 3 \mathrm{cms}$ mass lesion. Rest of the abdomen appeared normal. Biopsy revealed Sertoli-Leydig cell tumor of intermediate grade differentiation. Biopsy from right ovary and omentum were normal.

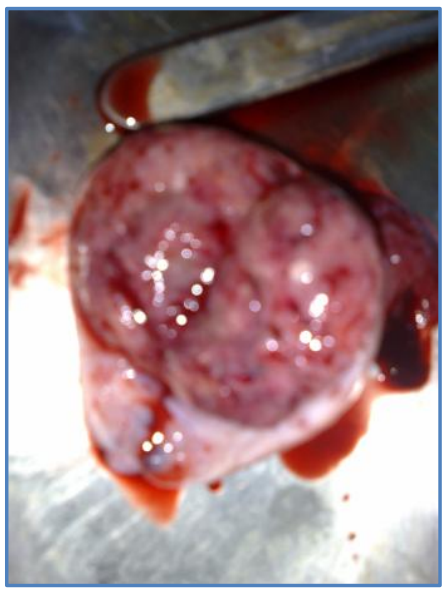

\section{Fig. 3: Cut section of ovary with encapsulated tumor}

Patient was kept on cyclical oral contraceptive pills and she resumed regular cycles. Post operatively hirsutism, clitoromegaly, decreased. Hoarseness decreased over a course of 6 months.patient is under regular follow-up. She got married and delivered a healthy male baby after two years of surgery. Need for radiotherapy excluded by radiotherapist. 
COMMENT: Menstrual irregularities are the most common hormone related manifestation. If virilizing signs are present menstrual irregularities are universal. ${ }^{2}$ Androgen excess result in defeminization. Breast atrophy, loss of sub cutaneous deposits and female contour are common.

In Women with androgen secreting sertoli-leydig cell tumors growth of facial and body hair, development of acne and external genitalia occur in about 33-38\% of cases.1-2 Deepening of voice is noted in $75 \%$ of virilized patients. Zaloudek and Norris ${ }^{3}$ have the largest series in which the incidence of virilizing signs is reported.

Clitoral hypertrophy, defined as clitoral length more than $2 \mathrm{~cm}$ is seen in approximately half of virilized patients. After tumor resection many androgenic manifestations resolve over time. ${ }^{1-2}$ virilizing symptoms of clitoromegaly, hirsutism, and deepening of voice regress less reliably. ${ }^{1}$ Abdominal pain, discomfort and swelling noted in about $15 \%$.

Ultrasound remains the best imaging modality, but normal ultrasound findings in presence of clinical and laboratory evidence of androgen excess cannot exclude the diagnosis. Computerized tomography is helpful in differentiating it from adrenal tumors. Study of tumor markers such as inhibin and AFP are useful to study the response to therapy in patients with advanced or recurrent SL tumors

Hormonal studies are useful to differentiate between ovarian and adrenal tumors. Patients who demonstrate signs of virilization will have elevated plasma testosterone. Urinary 17-alpha ketosteroids are usually normal or slightly elevated ${ }^{1,2}$, and 4 in contrast to adrenal tumors.

Ovarian and adrenal venography with selective venous sampling is considered as "gold standard" for localizing androgen secreting tumors. ${ }^{4}$ 97\% of tumors are diagnosed at stage 1 due to early androgenic manifestations. Well differentiated tumors are benign. Moderately and poorly differentiated tumors have malignant potential ranging from 3-34\%. SLCT having retiform pattern are associated with $20 \%$ malignancy rate.

Young woman desirous of childbearing should be treated with unilateral salpingooopherectomy.in older woman TAH with bilateral salpingo-oophorectomy is the treatment of choice. Chemotherapy and radiotherapy can be considered for recurrence.

CONCLUSION: Whenever a young girl presents with menstrual disturbances and hirsutism with elevated androstenidione levels, Sertoli-Leydig cell tumor should be suspected and unilateral salpingo-oophorectomy often gives good results.

\section{REFERENCES:}

1. Serov SF, Scully RE, Sobin LH. International histologic classification of tumors, no. 9. Histological typing of ovarian tumors, WHO, Geneva 1973.

2. Young RH, Scully RE. Ovarian sertoli-Leydig cell tumors: a clinic pathological analysis of 207 cases. Am J Surg Path 1985:9(8):543.

3. Zaloudek C. Norris HJ. Sertoli-Leydig tumors of the ovary: a clinicopathologic study of 64 intermediate and poorly differentiated neoplasms Am J Surg path 1984:8(6)

4. Weiland AJ Bookstein JJ. Preoperative localisation of virilizing tumors by selective venous sampling. Am J Obstet Gynecol1987; 131:797. 


\section{CASE REPORT}

\section{AUTHORS:}

1. Lavanya Kumari Sarella

2. D. Usha Sree

\section{PARTICULARS OF CONTRIBUTORS:}

1. I/C Professor, Department of Obstetrics and Gynaecology, Rangaraya Medical College,

2. Assistant Professor, Department of Obstetrics and Gynaecology, Rangaraya Medical College,

\section{NAME ADDRESS EMAIL ID OF THE} CORRESPONDING AUTHOR:

Dr. Lavanya Kumari Sarella,

\#66-10-1/17,

Narasanna Nagar,

Kakinada - 533003,

Andhra Pradesh.

E-mail: lavanyakumarisarella@yahoo.com

Date of Submission: 12/03/2014. Date of Peer Review: 13/03/2014.

Date of Acceptance: 20/03/2014.

Date of Publishing: 02/04/2014. 